\title{
Association between Self-Reported Habitual Snoring and Diabetes Mellitus: A Systemic Review and Meta-Analysis
}

\author{
Xiaolu Xiong, ${ }^{1}$ Anyuan Zhong, ${ }^{2}$ Huajun $\mathrm{Xu}^{3}{ }^{3}$ and Chun Wang ${ }^{4}$ \\ ${ }^{1}$ Department of Endocrinology, Drum Tower Clinical Medical College of Nanjing Medical University, \\ 53 North Zhongshan Road, Nanjing 210008, China \\ ${ }^{2}$ Department of Respiratory Diseases, The Second Affiliated Hospital of Soochow University, 1055 Sanxiang Road, \\ Suzhou 215004, China \\ ${ }^{3}$ Department of Otolaryngology, Shanghai Jiao Tong University Affiliated Sixth People's Hospital, \\ Otolaryngology Institute of Shanghai Jiao Tong University, 600 Yishan Road, Shanghai 200233, China \\ ${ }^{4}$ Department of Geriatrics, Drum Tower Clinical Medical College of Nanjing Medical University, 53 North Zhongshan Road, \\ Nanjing 210008, China \\ Correspondence should be addressed to Huajun Xu; sunnydayxu2010@sjtu.edu.cn and Chun Wang; wcglyy@163.com
}

Received 7 September 2015; Accepted 13 December 2015

Academic Editor: Geoff Werstuck

Copyright ( 2016 Xiaolu Xiong et al. This is an open access article distributed under the Creative Commons Attribution License, which permits unrestricted use, distribution, and reproduction in any medium, provided the original work is properly cited.

\begin{abstract}
Aim. Several studies have reported an association between self-reported habitual snoring and diabetes mellitus (DM); however, the results are inconsistent. Methods. Electronic databases including PubMed and EMBASE were searched. Odds ratios (ORs) and $95 \%$ confidence intervals (CIs) were used to assess the strength of the association between snoring and DM using a randomeffects model. Heterogeneity, subgroup, and sensitivity analyses were also evaluated. Begg's, Egger's tests and funnel plots were used to evaluate publication bias. Results. A total of eight studies (six cross sectional and two prospective cohort studies) pooling 101,246 participants were included. Of the six cross sectional studies, the summary OR and 95\% CI of DM in individuals that snore compared with nonsnorers were 1.37 (95\% CI: 1.20-1.57, $p<0.001$ ). There was no heterogeneity across the included studies $\left(I^{2}=2.9 \%, p=0.408\right)$. When stratified by gender, the pooled OR $(95 \% \mathrm{CI})$ was $1.59(1.20-2.11)$ in females $(n=12298)$, and 0.89 $(0.65-1.22)$ in males $(n=4276)$. Of the two prospective studies, the pooled RR was 1.65 (95\% CI, $1.30-2.08)$. Conclusions. Selfreported habitual snoring is statistically associated with DM in females, but not in males. This meta-analysis indicates a need to paying attention to the effect of snoring on the occurrence of DM in females.
\end{abstract}

\section{Introduction}

Diabetes mellitus (DM) is becoming a major global public health problem. Compared with 1980s, the proportion of diabetes of both men $(9.8 \%$ versus $8.3 \%)$ and women $(9.2 \%$ versus $7.5 \%$ ) increased in 2008 [1]. It is worthwhile to note that over 438 million individuals are expected to be at risk of developing DM by 2030 [2]. Besides its high prevalence, growing research also suggests that DM could induce adverse health implication $[3,4]$. Similarly, habitual snoring is a common and early symptom of obstructive sleep apnea (OSA) and affects $\sim 33 \%$ of the general population [5]. Snoring has long been considered a nuisance especially for bed partners and brought social burden (i.e., traffic accident and poor school performance) [6-8]. An increasing amount of evidence has also suggested that habitual snoring might be associated with health-related complications, including endothelial dysfunction, vascular injury, stroke, and cardiovascular diseases [6, 9-12].

Many studies have assessed the association between selfreported habitual snoring and DM. However, conflicting results have been reported. Importantly, habitual snoring might help doctors identify individuals at a higher risk of developing DM. Therefore, the relationship between these two common diseases should be evaluated comprehensively.

To our knowledge, a quantitative analysis evaluating the association between self-reported habitual snoring and DM susceptibility is not available. Thus, it is essential to perform 
a meta-analysis to clarify this potential association. The purpose of the current study was to identify the association between self-reported snoring and DM by performing pooled risk estimates.

\section{Materials and Methods}

We performed this meta-analysis according to the recommendations of Meta-analysis Of Observational Studies in Epidemiology (MOOSE) statement [13].

2.1. Literature Search Strategy. To identify studies that assessed the relationship between self-reported snoring and susceptibility to DM, we searched electronic databases systemically, including PubMed and EMBASE in May 2015. No language and human study restriction were imposed. The following combinations of $\mathrm{MeSH}$ terms and text word terms were used (snoring or snorer or self-reported snoring) and (diabetes or diabetic or diabetes mellitus or hyperglycemia). We also checked the reference lists of relevant articles that might be appropriate for inclusion in the meta-analysis. The searches were conducted by Drs. Xiong and Zhong, respectively.

2.2. Inclusion and Exclusion Criteria. Studies that met the following criteria were included: (1) studies that evaluated self-reported snoring and the risk of DM; (2) prospective observational, retrospective, cohort, cross-sectional, or casecontrolled studies; (3) subjects without a diagnosis of DM at baseline or who were excluded from the final statistical analysis; (4) odds ratios (ORs) or risk ratios (RRs) and 95\% confidence intervals (CIs) which were provided for comparing snorers to nonsnorers; (5) snoring status which was defined using the question "To the best of your knowledge, do you snore now or have you snored previously?" and habitual snoring which was defined by each study; (6) the definition of diabetes which was mainly according to a history of diagnosis made by a physician, fasting serum glucose levels, oral glucose tolerance test (OGTT), or the use of medicine to treat DM. Studies were excluded if (1) it was not a fulltext paper (i.e., no reviews, abstracts, letters, or comments); (2) snoring was not measured using a questionnaire; (3) it analyzed subjects with gestational diabetes mellitus; (4) no variables were adjusted.

2.3. Data Extraction. Two authors (Drs. Xiong and Zhong) extracted the data from the included studies to a standard sheet independently. The data extracted includes the first author and year of publication, country of origin, source of the study, study design, sample size, percentage of female participants, age range, OR or RR with $95 \% \mathrm{CI}$, adjusted variables, the measurement used to assess snoring, and the diagnosis of DM. If there were discrepancies in the basic information of the included studies, a third reviewer (Dr. $\mathrm{Xu}$ ) examined the inconsistent extracted data. If there were additional queries or if further details were needed, the authors of the original studies were contacted via email.
2.4. Quality Assessment. The methodological quality of all included studies was assessed according to the NewcastleOttawa scale (NOS) guidelines (http://www.ohri.ca/programs/ clinical_epidemiology/oxford.asp). A study was awarded a maximum of one star for each numbered item within the selection and outcome categories. Therefore, a maximum of four, three, and two stars were given for selection, outcome, and comparability, respectively. More stars indicated a higher quality study. We recognized one star as one score, and the score of each study was presented in Table 1.

2.5. Statistical Analysis. ORs, RRs, and 95\% CIs were used to assess the relationship between self-reported snoring and DM across the included studies. The ORs were transformed into RRs using the formula $\mathrm{RR}=\mathrm{OR} /\left[\left(1-P_{o}\right)+\left(P_{o} *\right.\right.$ $\mathrm{OR})]$ ( $P_{o}$ is the incidence of the outcome of interest in the nonexposed group). If an included study reported various adjustments for covariates, the most fully adjusted OR/RR was used in pooled analysis. Heterogeneity was examined using Cochrane $Q$ tests and the $I^{2}$ statistic [14]. If betweenstudy heterogeneity existed $\left(p<0.10\right.$ or $\left.I^{2}>50 \%\right)$, a random-effects model was used; otherwise a fixed-effect model was applied [15]. Subgroup analysis was performed to assess the effect of significant group differences according to gender. Sensitivity analysis was performed to test the robustness of the results by omitting one study each time. Potential publication bias was assessed using Begg's rank correlation and Egger linear regression tests [16]. Unless stated otherwise, $p<0.05$ was considered to be statistically significant. All the above-mentioned statistical analyses were performed using the STATA software (version 12.0, Stata Corp., College Station, TX, USA).

\section{Results}

3.1. Literature Search Results. A total of 497 potentially relevant references were retrieved from the PubMed and EMBASE databases. 31 duplicates were removed. After first reviewing the titles and abstracts, 449 studies were further excluded for various reasons. The remaining 17 papers were reviewed fully, and a further nine reported papers were excluded for evaluating self-reported snoring and gestational DM $(n=5)$, self-reported snoring and metabolic syndrome $(n=2)$, and self-reported snoring and hemoglobin Alc levels, glucose, and insulin metabolism $(n=2)$. Finally, eight studies were enrolled in the qualitative synthesis, among which six were included in the meta-analysis. The detailed search process is presented in Figure 1.

3.2. Characteristics of the Included Studies. A total of eight studies (including six cross-sectional and two prospective cohort studies) pooling 101,246 participants were included. The mean age of the participants at baseline ranged from 20 to 85 years. The percentage of female subjects ranged from $48.8 \%$ to $100 \%$, except for one study that enrolled only male subjects. Three of the included studies were performed in the United States [17, 22, 23], three were conducted in Sweden $[1,18,21]$, and one was undertaken in each of Finland [19] 
TABLE 1: Characteristics of included studies in this meta-analysis.

(a)

\begin{tabular}{|c|c|c|c|c|c|c|c|}
\hline $\begin{array}{l}\text { First author } \\
\text { Year }\end{array}$ & Country & $\begin{array}{c}\text { Source and study } \\
\text { type }\end{array}$ & $\begin{array}{l}\text { Sample } \\
\text { size }\end{array}$ & $\begin{array}{c}\text { Female } \\
(\%)\end{array}$ & $\begin{array}{c}\text { Age } \\
\text { range }\end{array}$ & OR or RR $(95 \% \mathrm{CI})$ & Adjusted variables \\
\hline $\begin{array}{l}\text { Sabanayagam } \\
2012 \text { [17] }\end{array}$ & America & $\begin{array}{l}\text { Population-based } \\
\text { Cross-sectional }\end{array}$ & 6522 & 48.8 & $20-85$ & $1.44(1.16-1.79)^{\mathrm{a}}$ & $\begin{array}{c}\text { Age, sex, ethnicity, education, } \\
\text { smoking, alcohol, physical activity, } \\
\text { BMI, depression, SBP, CRP, and } \\
\text { TC }\end{array}$ \\
\hline $\begin{array}{l}\text { Valham } \\
2009[18]\end{array}$ & Sweden & $\begin{array}{l}\text { Population-based } \\
\text { Cross-sectional }\end{array}$ & 7905 & 51.2 & $25-79$ & $\begin{array}{l}\text { Female: } 1.58(1.02-2.44)^{\mathrm{a}} \\
\text { Male: } 0.92(0.64-1.33)^{\mathrm{a}}\end{array}$ & $\begin{array}{l}\text { Smoking, age, BMI, and waist } \\
\text { circumference }\end{array}$ \\
\hline $\begin{array}{l}\text { Renko } \\
2005 \text { [19] }\end{array}$ & Finland & $\begin{array}{l}\text { Population-based } \\
\text { Cross-sectional }\end{array}$ & 593 & 58.7 & $61-63$ & $1.93(1.04-3.57)^{\mathrm{a}}$ & $\begin{array}{c}\text { Age, weight gain, smoking, alcohol } \\
\text { dependence, and physical } \\
\text { inactivity }\end{array}$ \\
\hline $\begin{array}{l}\text { Marchesini } \\
2004[20]\end{array}$ & Italy & $\begin{array}{l}\text { Population-based } \\
\text { Cross-sectional }\end{array}$ & 1890 & 78 & $20-65$ & $\begin{array}{c}1.31(0.95-1.81)^{\mathrm{a}} \\
\text { Female: } 1.62(1.11-2.36)^{\mathrm{a}} \\
\text { Male: } 0.81(0.45-1.50)^{\mathrm{a}}\end{array}$ & Age, sex, and BMI \\
\hline $\begin{array}{l}\text { Lindberg } \\
2007[21]\end{array}$ & Sweden & $\begin{array}{l}\text { Population-based } \\
\text { Cross-sectional }\end{array}$ & 6779 & $100 \%$ & $20-99$ & $\begin{array}{l}\text { No EDS: } 1.36(0.87-2.13)^{\mathrm{a}} \\
\text { EDS: } 1.82(0.97-3.43)^{\mathrm{a}}\end{array}$ & $\begin{array}{l}\text { Age, BMI, smoking, physical } \\
\text { activity, and alcohol dependency }\end{array}$ \\
\hline $\begin{array}{l}\text { Enright } \\
1996[22]\end{array}$ & America & $\begin{array}{l}\text { Population-based } \\
\text { Cross-sectional }\end{array}$ & 5201 & $57 \%$ & $\geq 65$ & Women: $1.34(0.10-1.65)^{\mathrm{a}}$ & Age and being married \\
\hline $\begin{array}{l}\text { Al-Delaimy } \\
2002[23]\end{array}$ & America & $\begin{array}{l}\text { Population-based } \\
\text { Prospective cohort }\end{array}$ & 69852 & $100 \%$ & $40-65$ & $1.63(1.29-2.07)^{\mathrm{b}}$ & $\begin{array}{l}\text { Age, high TC, high BP, smoking, } \\
\text { BMI, physical activity, alcohol use, } \\
\text { postmenopausal hormone use, } \\
\text { family history of diabetes, sleeping } \\
\text { position, sleep time, years of } \\
\text { shift-work, and WHR }\end{array}$ \\
\hline $\begin{array}{l}\text { Elmasry } \\
2000[1]\end{array}$ & Sweden & $\begin{array}{l}\text { Population-based } \\
\text { Prospective cohort }\end{array}$ & 2504 & $0 \%$ & $30-69$ & $\begin{array}{l}\text { Nonobese: } 1.06(0.36-3.1)^{\mathrm{a}} \\
\text { Obese: } 7.0(2.9-16.9)^{\mathrm{a}}\end{array}$ & $\begin{array}{l}\text { Age, weight gain, smoking, alcohol } \\
\text { dependence, and physical } \\
\text { inactivity }\end{array}$ \\
\hline
\end{tabular}

(b)

Definition of snoring

Assessment/definition of DM

Presence of NOS

Serum glucose $\geq 126 \mathrm{mg} / \mathrm{dL}$ after fasting for a minimum of 8 hours, a plasma glucose $\geq 200 \mathrm{mg} / \mathrm{dL}$ for those who fasted $<8$

Questionnaire answer: never or rare, occasionally as nonhabitual snorers; frequently as habitual snorers

hours or HbAlc $\geq 6.5 \%$, a self-reported DM or current use of comorbidities score

Questionnaire answer: always or often as habitual snorers; sometimes, never, or almost never as nonhabitual snorers Questionnaire answer: those who reported snoring every or almost every night were classified as habitual snorers Questionnaire answer: occasional or habitual as habitual snorers Questionnaire answer: how often they snored using a five-point scale; snoring was defined as a score of 3-5

Questionnaire answer: yes or no or don't know; yes as habitual snorers

Questionnaire answer: regularly as habitual snorers; occasionally or never oral hypoglycemic medication or insulin

Questionnaire answer: "Do you suffer from DM?"

Previously diagnosed DM, OGTT according to WHO criteria in 1998

Previously diagnosed DM, OGTT according to WHO criteria in 1998

Questionnaire answer: "Do you have diabetes?" and/or attended regular medical examinations for diabetes

History of DM, current use of insulin or oral hypoglycemic medication, fasting glucose $\geq 140 \mathrm{mg} / \mathrm{dL}$, or 2-hour postload glucose $\geq 200 \mathrm{mg} / \mathrm{dL}$.

Classic symptoms associated with an elevated plasma glucose level or no symptoms, but at least two elevated plasma glucose values on different occasions; or treatment with hypoglycemic medication

Questionnaire answer: a five-point scale:

$\geq 4$ was defined as habitual snorers; $\leqq 3$ Questionnaire: self-report DM or confirmed by medical records was defined as nonhabitual snorers

OR, odds ratio; RR, risk ratio; BMI, body mass index; SBP, systolic blood pressure; CRP, C reactive protein; TC, cholesterol; BP, blood pressure; DM, diabetes mellitus; HbAlc, glycosylated hemoglobin; OGTT, oral glucose tolerance test; WHO, World Health Organization; NOS: Newcastle-Ottawa scale. Note: a means studies report OR, while b means study reports RR. 


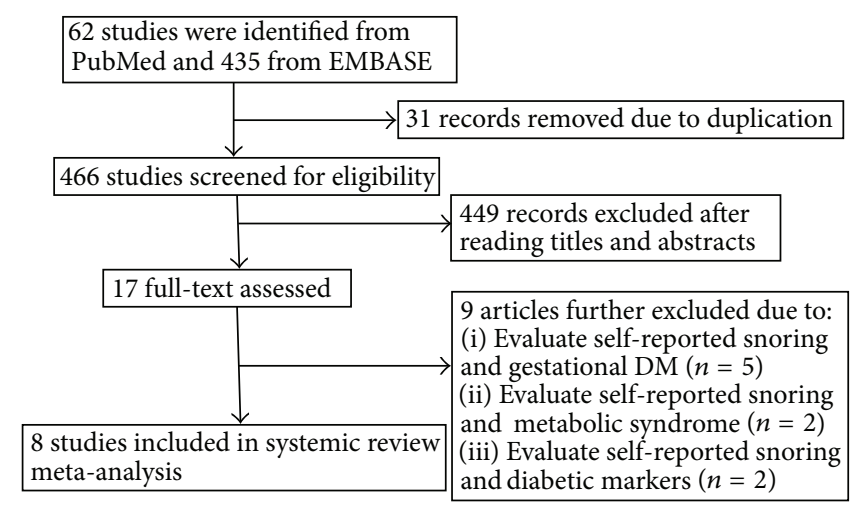

FIGURE 1: Flow chart of the literature search and study selection process.

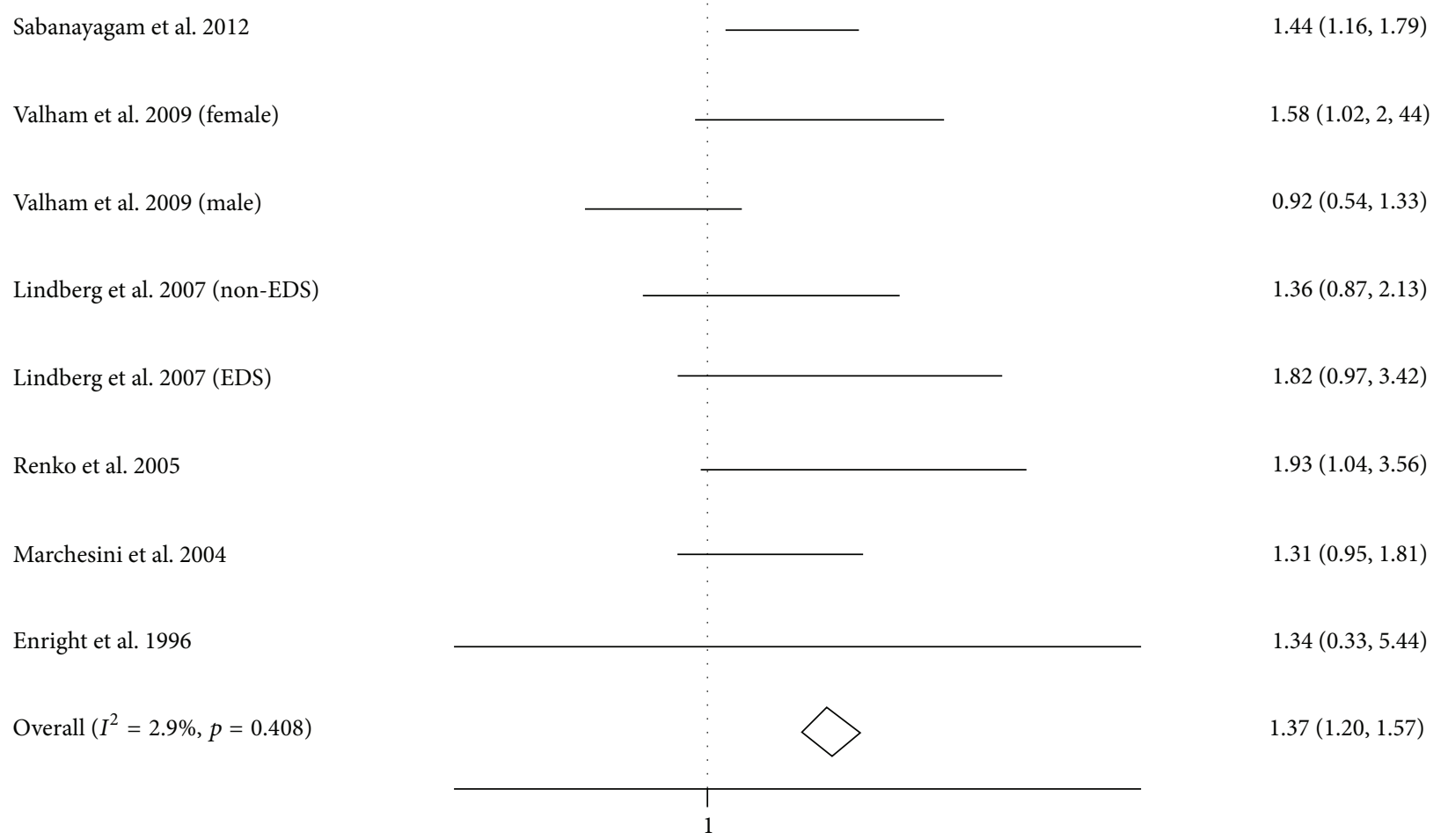

FIGURE 2: Forest plot of the association between self-reported habitual snoring and diabetes mellitus risk. Valham et al's study provided the data in female and male population not the whole population, and Lindberg et al's study provided the data in excessive daytime sleepiness (EDS) and non-EDS snorers.

and Italy [20]. All the included studies were observational and population-based; six were designed as cross-sectional studies, and the other two $[1,23]$ were prospective cohorts. The follow-up duration of the two prospective studies was 10 years. Three of the included studies got a high score of eight, and the other five studies scored seven in quality assessment. The detailed properties of the studies are summarized in Table 1 .

3.3. Pooled and Subgroup Analysis: Snoring and Risk for DM. In this meta-analysis, we summarized the mostly adjusted
ORs and 95\% CIs by pooling the six cross-sectional studies containing 28,890 subjects. Of the six studies, one study provided the data in female and male population not the whole population [18], and the other study provided the data in excessive daytime sleepiness (EDS) and non-EDS snorers [21]. The OR and 95\% CI of DM in individuals with selfreported habitual snoring compared with nonsnorers were 1.37 (95\% CI, 1.20-1.57, $p<0.001$ ) (Figure 2). There was no heterogeneity across the included studies $\left(I^{2}=2.9 \%\right.$, $p=0.408)$.

In subgroup analysis of the six cross-sectional studies, only two studies stratified according to gender $[18,20]$, and 


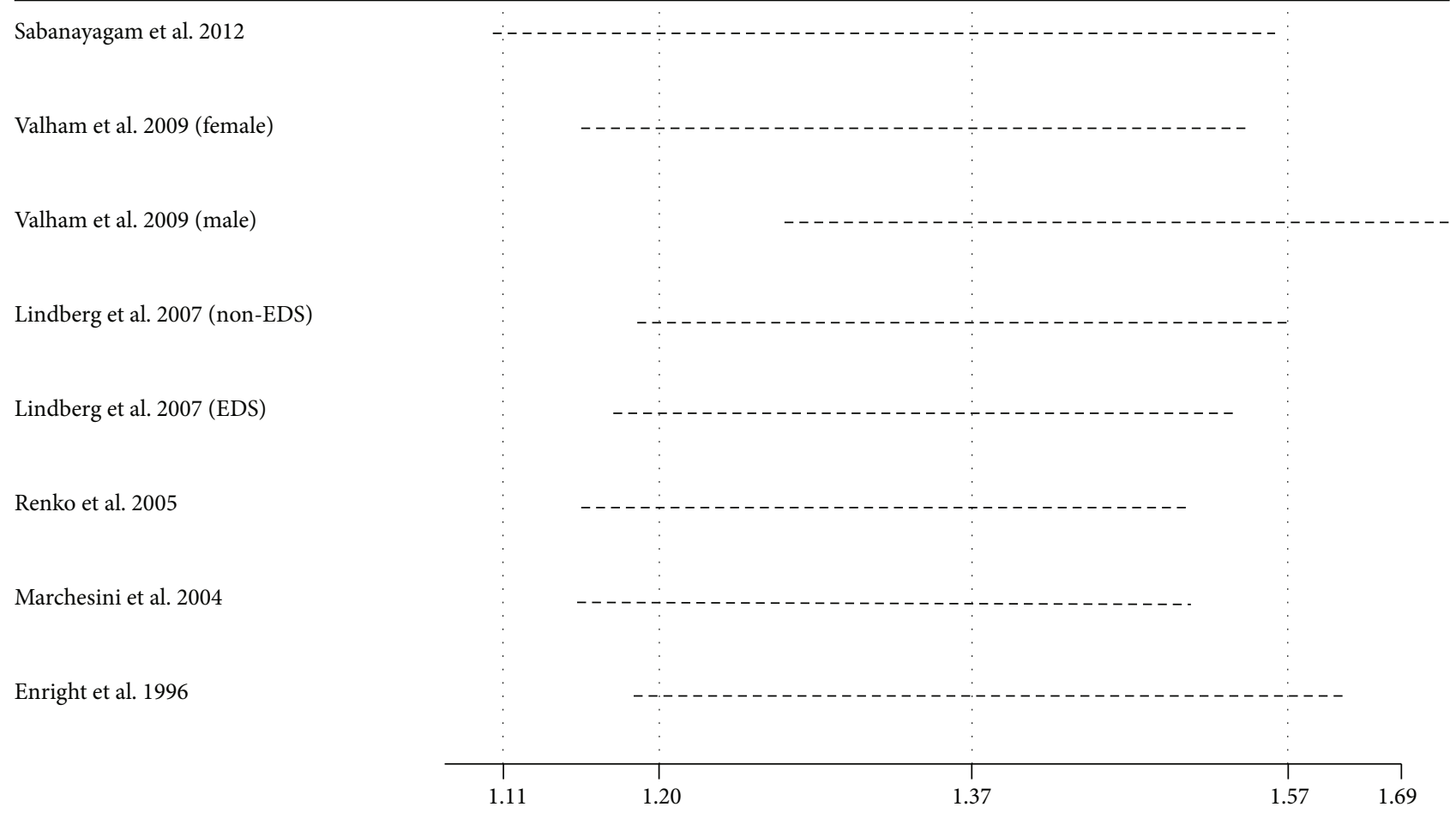

FIGURE 3: Effect of individual studies on the pooled OR for the self-reported habitual snoring and diabetes mellitus risk.

one study was conducted in a female population [21]. In the female population $(n=12298)$, the pooled OR was $1.59(95 \%$ CI, 1.20-2.11), whereas OR $=0.89(95 \% \mathrm{CI}, 0.65-1.22)$ in the male population $(n=4276)[18,20]$.

For the two prospective cohort studies, one study [23] was conducted in a female population of 69,852 subjects; the RR was 1.63 (95\% CI, 1.29-2.07). The second study [1] was conducted in a male population of 2,504 subjects, and the RR was 1.06 (95\% CI, 0.36-3.1) and 7.0 (95\% CI, 2.9-16.9) in nonobese and obese populations, respectively. The pooled RR of the two prospective studies was 1.65 (95\% CI, 1.30-2.08).

3.4. Sensitivity Analysis. Sensitivity analyses were performed to verify the robustness of the results. These separate statistical analyses were conducted by omitting one study each time. The OR (95\% CI) estimates ranged from 1.42 (1.27-1.60) to 1.54 (1.37-1.74). The data suggested that no individual study affected the results in the meta-analysis (Figure 3 ).

3.5. Publication Bias. To assess publication bias among the included cross-sectional studies, Begg's rank correlation tests and Egger linear regression tests were performed; the $p$ value of these two tests was 0.386 and 0.648 , respectively. No asymmetrical funnel plots were found, as shown in Figure 4.

\section{Discussion}

This meta-analysis of six cross-sectional and two prospective cohort studies with a total of 101,246 participants revealed a statistically significant association between self-reported habitual snoring and DM. When stratified according to gender, there was a strong association between snoring and $\mathrm{DM}$ in females, but not in males.

Snoring affects both genders, including $23 \%$ of middleaged males and $10 \%$ of females [24]. Obese subjects have a higher proportion of snoring than do the nonobese general population (45\% versus 35\%) [25]. Interestingly, the current meta-analysis stratified the studies according to gender, which revealed that females with habitual snoring were found to be associated with DM (OR, 1.59; 95\% CI, 1.20-2.11). Conversely, there was no statistical significance in males (OR, 0.89; 95\% CI, 0.65-1.22). Two prospective cohort studies also revealed the same phenomenon: RR 1.63 (1.29-2.07) in females and OR $1.06(0.36-3.1)$ in nonobese males $[1,23]$. The reasons why females who snore habitually are more associated with DM than males are as follows: (1) the average age of women who suffer sleep disordered breathing was older than males; (2) polycystic ovary syndrome (PCOS) is a common condition in premenopausal women (7\%); women who have PCOS are more likely to develop into DM and sleep apnea [18]. Other variables such as age and BMI could not be included in further subgroup analysis due to limited data in the included studies.

Currently, many snorers ignore the adverse health effects that are caused by snoring. Although the relationship between habitual snoring and DM has been established, the exact mechanisms for this association have not been elucidated completely. Snoring is a sign of compromised upper airways and OSA and is characterized by the recurrent collapse of respiratory structures during breathing while asleep 


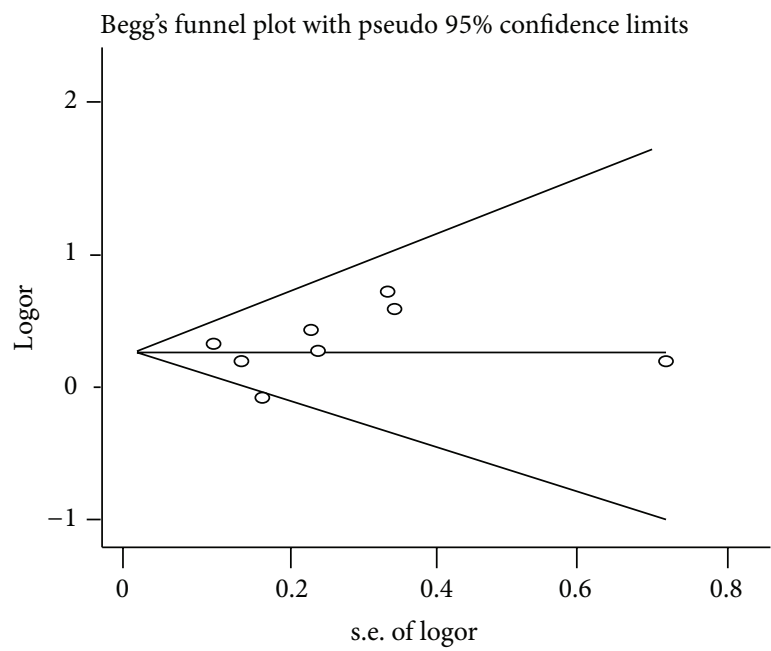

FIGURE 4: Funnel plot of the association between the self-reported habitual snoring and diabetes mellitus risk.

[26]. Nocturnal intermittent hypoxia and hypercapnia might contribute to increased sympathetic nervous activity and increased oxidative stress, which finally lead to insulin resistance [27]. The activation of proinflammatory cytokine production also plays an important role in the progression of snoring-induced DM [28]. Snoring was also closely associated with atherosclerosis and cardiovascular diseases [29], which might be prone to DM development. Due to these adverse effects, self-reported snoring might be useful as a low-cost and noninvasive indicator during the screening of persons who are prone to DM, particularly in developing countries.

Several limitations must be addressed when interpreting the results of the current meta-analysis. First, the evidence in our meta-analysis is based mostly on observational studies; therefore, no inherent causality was addressed. Second, the definition of habitual snoring and the diagnostic criteria used for DM were inconsistent among the included studies; therefore, the misclassification of snoring and DM is inevitable. Third, unmeasured confounding variables could have affected the association between snoring and DM. Although we used the most fully adjusted estimates in each study, we cannot exclude the possibility that other confounders might have affected the association. Fourth, snoring might be an early marker of unmeasured OSA. However, none of the included studies use standard method to exclude OSA. That is to say, whether snoring without OSA might be prone to DM was undetermined. Finally, most of the included studies were cross-sectional, and so additional prospective cohort studies should be performed to explore the etiology of snoringinduced DM. Despite these limitations, this is the first metaanalysis to address the association between self-reported habitual snoring and DM, there was no heterogeneity, and sensitivity analysis revealed that the results were robust.

In conclusion, the current meta-analysis pooled eight studies and revealed that habitual snoring was associated with DM. However, it remains unclear how much of the susceptibility could be attributed to OSA. Additional well-designed studies with a larger sample size are warranted to validate these findings.

\section{Conflict of Interests}

The authors declare that they have no conflict of interests.

\section{Authors' Contribution}

Xiaolu Xiong and Anyuan Zhong contributed equally to this paper.

\section{References}

[1] A. Elmasry, C. Janson, E. Lindberg, T. Gislason, M. A. Tageldin, and G. Boman, "The role of habitual snoring and obesity in the development of diabetes: a 10 -year follow-up study in a male population," Journal of Internal Medicine, vol. 248, no. 1, pp. 1320, 2000.

[2] D. R. Whiting, L. Guariguata, C. Weil, and J. Shaw, "IDF diabetes atlas: global estimates of the prevalence of diabetes for 2011 and 2030," Diabetes Research and Clinical Practice, vol. 94, no. 3, pp. 311-321, 2011.

[3] R. I. G. Holt and A. J. Mitchell, "Diabetes mellitus and severe mental illness: mechanisms and clinical implications," Nature Reviews Endocrinology, vol. 11, no. 2, pp. 79-89, 2015.

[4] S. E. Kahn, M. E. Cooper, and S. Del Prato, "Pathophysiology and treatment of type 2 diabetes: perspectives on the past, present, and future," The Lancet, vol. 383, no. 9922, pp. 10681083, 2014.

[5] T. Young, P. E. Peppard, and D. J. Gottlieb, "Epidemiology of obstructive sleep apnea: a population health perspective," American Journal of Respiratory and Critical Care Medicine, vol. 165, no. 9, pp. 1217-1239, 2002.

[6] V. Deary, J. G. Ellis, J. A. Wilson, C. Coulter, and N. L. Barclay, "Simple snoring: not quite so simple after all?" Sleep Medicine Reviews, vol. 18, pp. 453-462, 2014.

[7] T. Abe, Y. Komada, and Y. Inoue, "Short sleep duration, snoring and subjective sleep insufficiency are independent factors 
associated with both falling asleep and feeling sleepiness while driving," Internal Medicine, vol. 51, no. 23, pp. 3253-3259, 2012.

[8] P. E. Brockmann, M. Schlaud, C. F. Poets, and M. S. Urschitz, "Predicting poor school performance in children suspected for sleep-disordered breathing," Sleep Medicine, vol. 16, no. 9, pp. 1077-1083, 2015.

[9] M. Li, K. Li, X.-W. Zhang, W. Hou, and Z. Tang, "Habitual snoring and risk of stroke: a meta-analysis of prospective studies," International Journal of Cardiology, vol. 185, pp. 46-49, 2015.

[10] D. Li, D. Liu, X. Wang, and D. He, "Self-reported habitual snoring and risk of cardiovascular disease and all-cause mortality," Atherosclerosis, vol. 235, no. 1, pp. 189-195, 2014.

[11] A. F. Cicero, M. Morbini, R. Urso et al., "Association between self-reported snoring and arterial stiffness: data from the Brisighella heart study," Internal and Emergency Medicine, pp. 1-7, 2015.

[12] J.-P. Baguet, P.-Y. Courand, B. Lequeux et al., "Snoring but not sleepiness is associated with increased aortic root diameter in hypertensive patients. The SLEEPART study," International Journal of Cardiology, vol. 202, pp. 131-132, 2016.

[13] D. F. Stroup, J. A. Berlin, S. C. Morton et al., "Meta-analysis of observational studies in epidemiology: a proposal for reporting," The Journal of the American Medical Association, vol. 283, no. 15, pp. 2008-2012, 2000.

[14] J. P. T. Higgins and S. G. Thompson, "Quantifying heterogeneity in a meta-analysis," Statistics in Medicine, vol. 21, no. 11, pp. 15391558, 2002.

[15] R. DerSimonian and R. Kacker, "Random-effects model for meta-analysis of clinical trials: an update," Contemporary Clinical Trials, vol. 28, no. 2, pp. 105-114, 2007.

[16] M. Egger, G. D. Smith, M. Schneider, and C. Minder, "Bias in meta-analysis detected by a simple, graphical test," British Medical Journal, vol. 315, no. 7109, pp. 629-634, 1997.

[17] C. Sabanayagam, S. Teppala, and A. Shankar, "Markers of sleep disordered breathing and diabetes mellitus in a multiethnic sample of US adults: results from the national health and nutrition examination survey (2005-2008)," International Journal of Endocrinology, vol. 2012, Article ID 879134, 8 pages, 2012.

[18] F. Valham, B. Stegmayr, M. Eriksson, E. Hägg, E. Lindberg, and K. A. Franklin, "Snoring and witnessed sleep apnea is related to diabetes mellitus in women," Sleep Medicine, vol. 10, no. 1, pp. 112-117, 2009.

[19] A.-K. Renko, L. Hiltunen, M. Laakso, U. Rajala, and S. Keinänen-Kiukaanniemi, "The relationship of glucose tolerance to sleep disorders and daytime sleepiness," Diabetes Research and Clinical Practice, vol. 67, no. 1, pp. 84-91, 2005.

[20] G. Marchesini, A. Pontiroli, G. Salvioli et al., "Snoring, hypertension and Type 2 diabetes in obesity. Protection by physical activity," Journal of Endocrinological Investigation, vol. 27, no. 2, pp. 150-157, 2004.

[21] E. Lindberg, C. Berne, K. A. Franklin, M. Svensson, and C. Janson, "Snoring and daytime sleepiness as risk factors for hypertension and diabetes in women-a population-based study," Respiratory Medicine, vol. 101, no. 6, pp. 1283-1290, 2007.

[22] P. L. Enright, A. B. Newman, P. W. Wahl, T. A. Manolio, E. F. Haponik, and P. J. R. Boyle, "Prevalence and correlates of snoring and observed apneas in 5,201 older adults," Sleep, vol. 19, no. 7, pp. 531-538, 1996.
[23] W. K. Al-Delaimy, J. E. Manson, W. C. Willett, M. J. Stampfer, and F. B. Hu, "Snoring as a risk factor for type II diabetes mellitus: a prospective study," American Journal of Epidemiology, vol. 155, no. 5, pp. 387-393, 2002.

[24] J. R. Stradling and J. H. Crosby, "Predictors and prevalence of obstructive sleep apnoea and snoring in 1001 middle aged men," Thorax, vol. 46, no. 2, pp. 85-90, 1991.

[25] B. Shahi, B. Praglowski, and M. Deitel, "Sleep-related disorders in the obese," Obesity Surgery, vol. 2, no. 2, pp. 157-168, 1992.

[26] N. M. Punjabi, "The epidemiology of adult obstructive sleep apnea," Proceedings of the American Thoracic Society, vol. 5, no. 2, pp. 136-143, 2008.

[27] N. Iiyori, L. C. Alonso, J. Li et al., "Intermittent hypoxia causes insulin resistance in lean mice independent of autonomic activity," American Journal of Respiratory and Critical Care Medicine, vol. 175, no. 8, pp. 851-857, 2007.

[28] I. Alam, K. Lewis, J. W. Stephens, and J. N. Baxter, "Obesity, metabolic syndrome and sleep apnoea: all pro-inflammatory states," Obesity Reviews, vol. 8, no. 2, pp. 119-127, 2007.

[29] S. A. Lee, T. C. Amis, K. Byth et al., "Heavy snoring as a cause of carotid artery atherosclerosis," SLEEP, vol. 31, no. 9, pp. 1207$1213,2008$. 


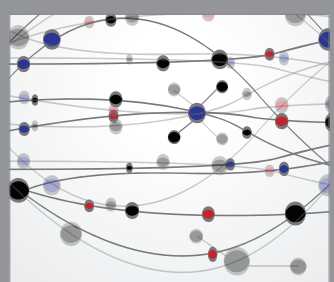

The Scientific World Journal
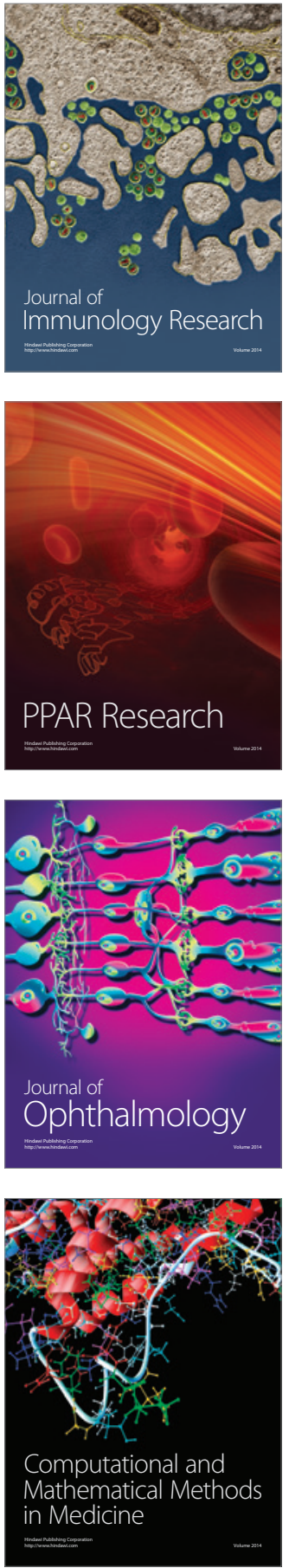

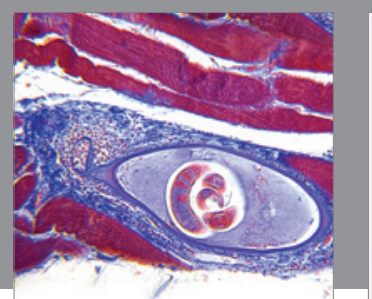

Gastroenterology Research and Practice

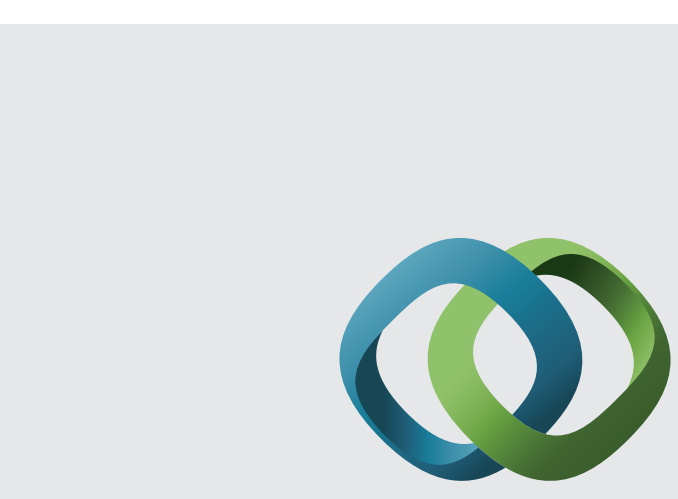

\section{Hindawi}

Submit your manuscripts at

http://www.hindawi.com
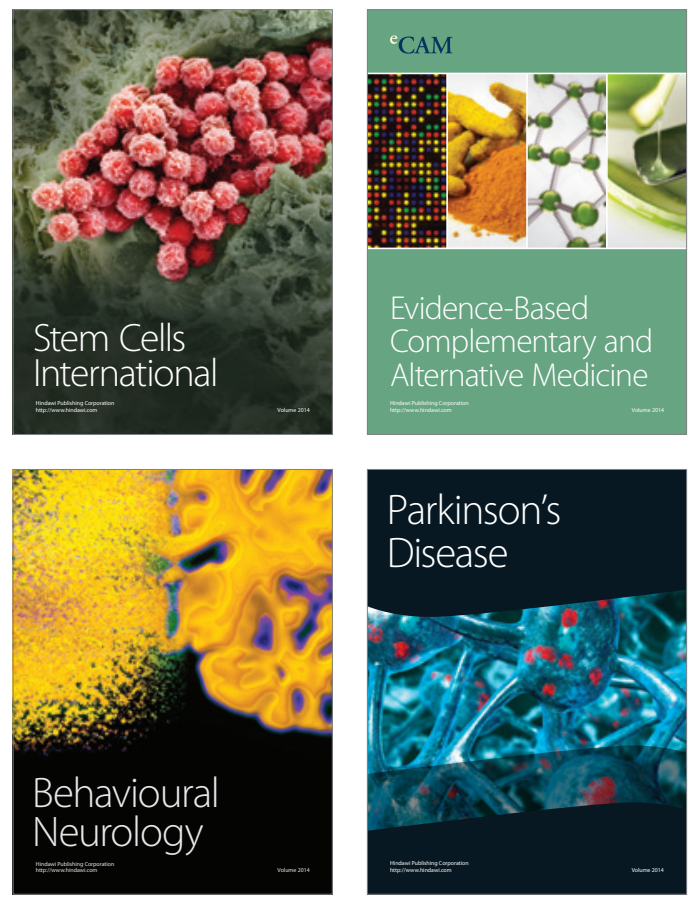
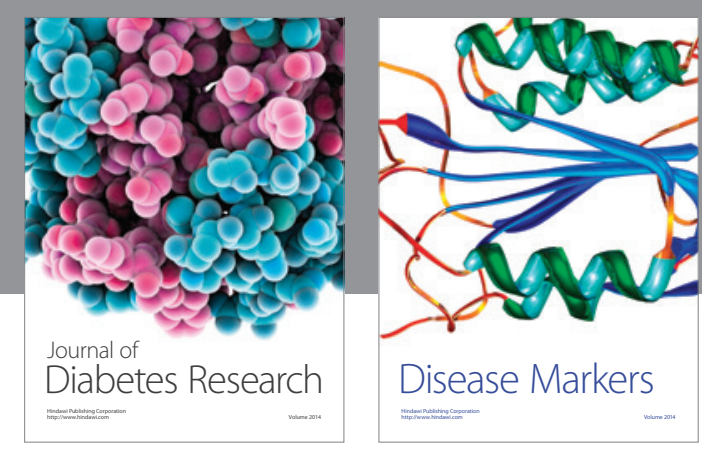

Disease Markers
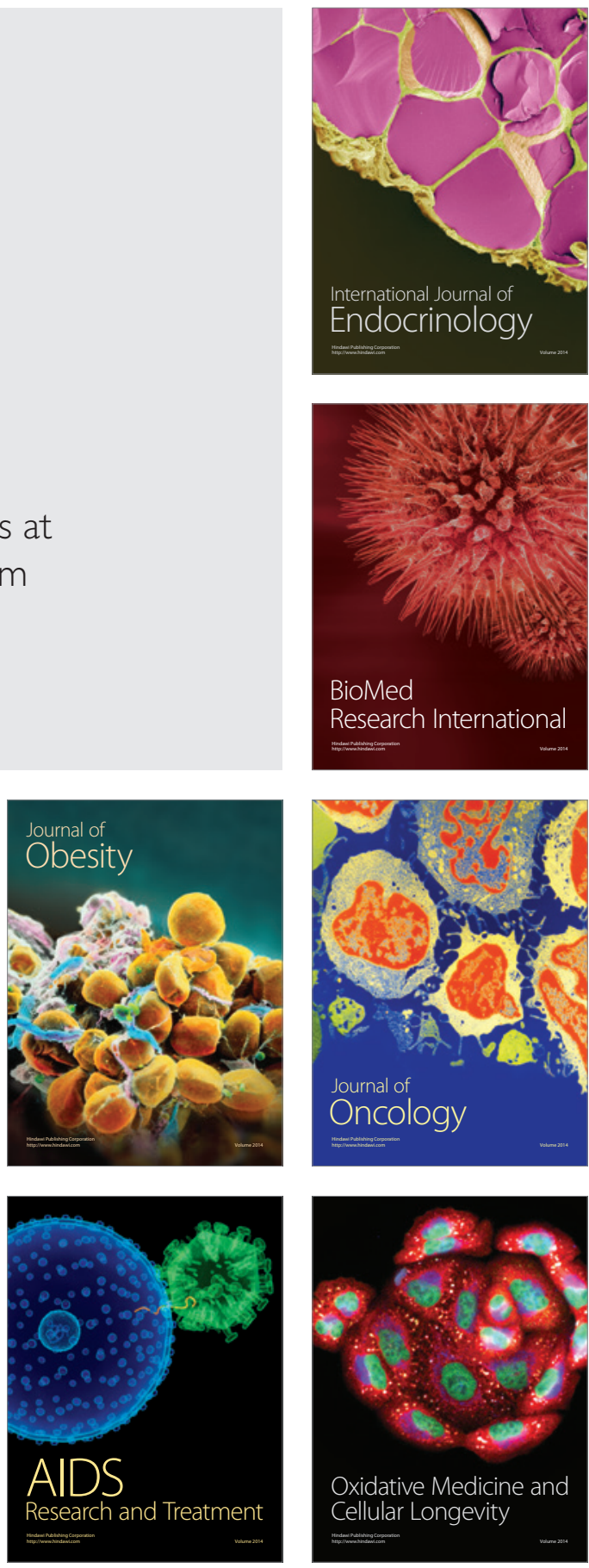